\section{RHABDOMYOSARCOMA OF THE URINARY BLADDER}

BY

\section{CLAUDE H. VIPOND, M.D., C.M., F.R.C.S.Ed. \\ Resident Surgical Officer, the Corbett Hospital, Stourbridge, Worcs.}

Rhabdomyosarcoma of the urinary bladder is a rare tumour the characteristics of which have been well reviewed by Khoury and Speer (1944). These writers have found eight cases in the literature, to which they have added a further case. A tenth (the first in this country) has been reported by Minchin (1947). Here is the report of a further case.

\section{Case Report}

A 21-months-old male child was admitted to hospital on June 1, 1947, having had retention of urine for twenty-one hours. The child had been healthy in all respects and had had no previous complaints before the onset of retention. At the time of admission there was some overflow incontinence, the bladder was apparently distended to the level of the umbilicus, and the child was in pain. A skiagram of abdomen and pelvis showed no opaque urethral calculus. After catheterization a firm mass was felt rising from the pelvic cavity to the level of the umbilicus. A tentative diagnosis of tumour of the bladder wall was made.

On June 5 a suprapubic cystotomy was performed by Mr. J. W. Riddoch under general anaesthesia. Exploration of the bladder revealed a firm smooth tumour occupying the posterior wall of the bladder and pushing that organ forward. The internal urethral meatus could be defined, and seemed to mark the lower limit of the growth. The impression was that this growth was covered only by the mucosa of the posterior bladder wa1l. On attempted biopsy the haemorrhage was severe. A de Pezzer catheter was inserted and the bladder wall closed in layers. The case was now considered to be one of myosarcoma of the bladder wall.

The patient became progressively emaciated and died of cachexia on Oct. 26-just under five months from the onset of symptoms. During the last few weeks of his life the suprapubic opening would no longer accommodate a catheter, and he discharged his urine through a narrow fistula.

One month before death his red cell count was $4,770,000$, white cell count 13,950 , and haemoglobin $71 \%$. His erythrocytic sedimentation rate was a $63-\mathrm{mm}$. fall in the first hour (Westergren technique). His blood urea at that time was 28.57 $\mathrm{mg}$. per $100 \mathrm{ml}$. During most of his illness the patient's temperature ranged from 99 to $99.8^{\circ} \mathrm{F}$. $\left(37.2-37.7^{\circ} \mathrm{C}\right.$.), but there were five or six periods of seven to ten days each in which the temperature fluctuated around $102^{\circ} \mathrm{F}$. $\left(38.9^{\circ} \mathrm{C}\right.$.). These probably coincided with exacerbations of his pyelonephritis.

Necropsy (Oct. 27).-A large tumour (Fig. 1) weighing about $1,788 \mathrm{~g}$. occupied and completely filled the pelvis, extending to

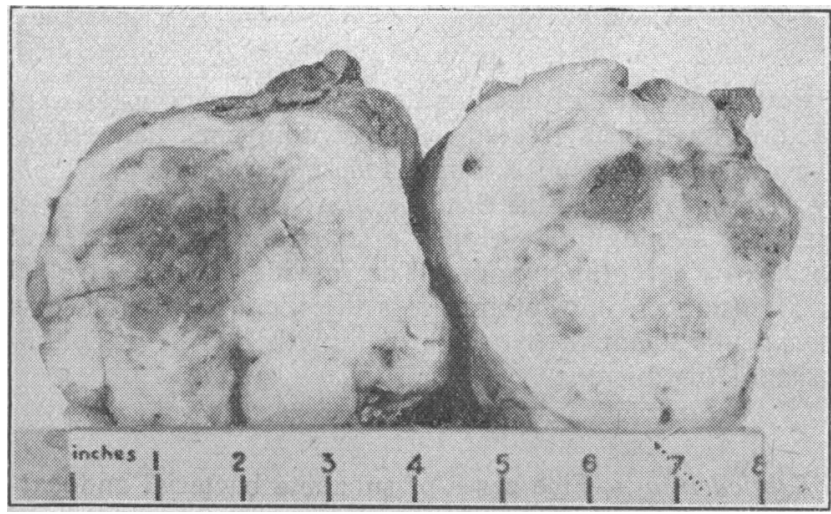

FIG. 1.-Showing lobulation and size of gross specimen.

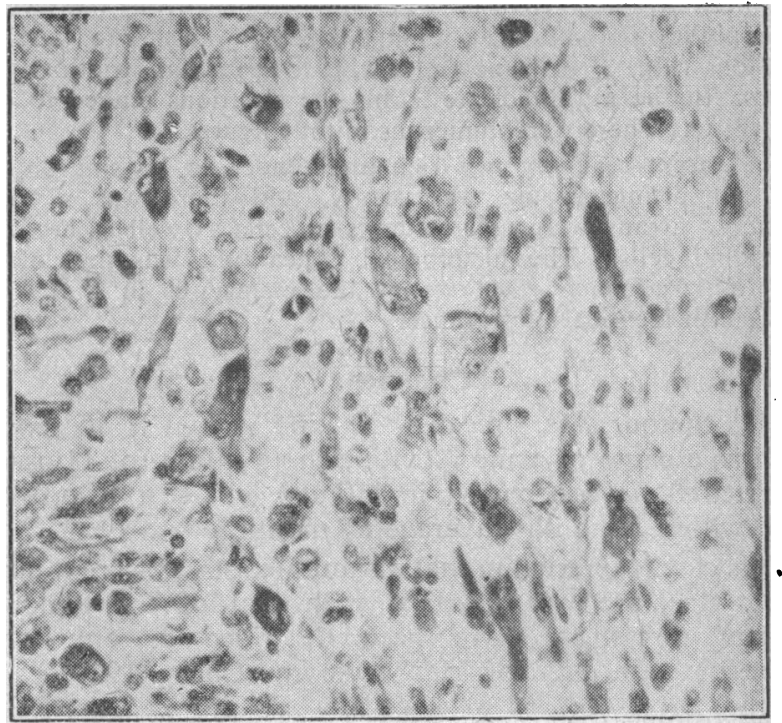

Fig. 2.-Showing the pleomorphism of the cells. $\times 300$

the level of the umbilicus. The tumour was entirely extraperitoneal. On macroscopic examination its surface was lobulated and the cut surface varied from clear gelatinous areas to others which were yellowish white and of firm consistency. There were some necrotic areas and slight interstitial haemorrhage. The peritoneal cavity contained about $50 \mathrm{ml}$. of blood-stained effusion. The visceral peritoneum was studded with small secondary nodules, especially marked in the great omentum. There were very few adhesions. The terminal part of the pelvic colon and the rectum were surrounded by growth, which appeared to have invaded their walls. The left lobe of the liver contained one large and several smaller metastases. The right lobe had several small metastases. Both kidneys were enlarged. The left showed a definite pyonephrosis and the right a hydronephrosis: The ureters were dilated and obstructed by the growth. Both ureteric orifices were found to be free from growth and there was no evidence that the walls of the ureters had been invaded. The bladder contained purulent urine. Both testes and spermatic cords were normal.

Histological Report.-Microscopical section of the tumour showed it to be richly cellular (Fig. 2). The cells were polymorphic and most of them had an oval nucleus with a prominent nucleolus and a well-marked chromatin network; the cytoplasm varied from a long rectangular type in some cells to a small perinuclear rim in others. There were also multinucleate forms containing two or three nuclei with a wide band of cytoplasm often

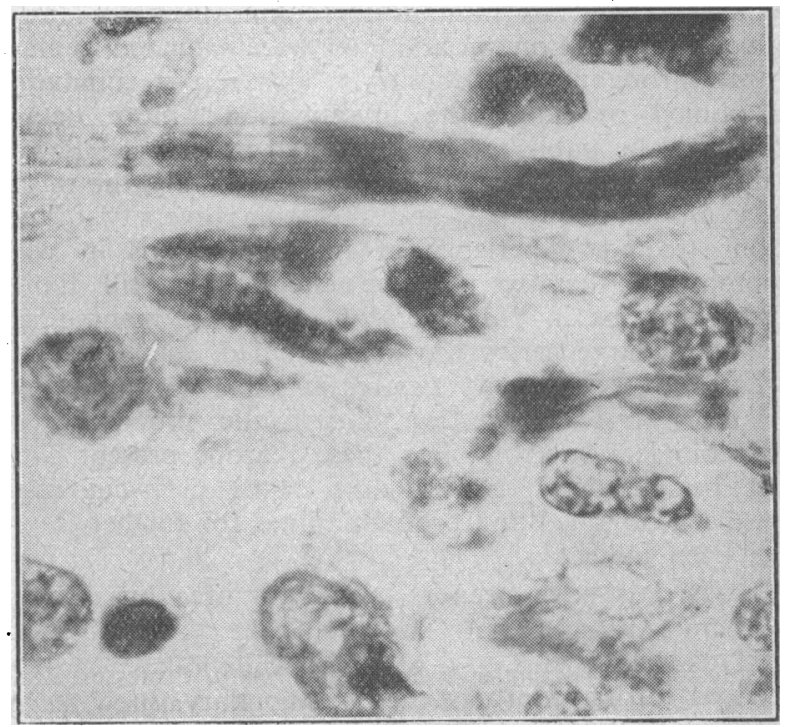

FIG. 3.-Showing the well-marked cross-striations. $\times 450$. 
prolonged at one side. In all cases the cytoplasm was markedly eosinophilic, and suitable staining revealed well-marked crossstriations (Fig. 3) in some cells, with longitudinal striations in others. In the multinucleate forms the striations tended to be concentric. There were numerous mitotic figures.

The vascular supply was rich and tended to be sinusoidal The supporting stroma was scanty, and there was a rich reticulum arranged around columns of cells as well as around individual cells. The histological appearance was that of a rhabdomyosarcoma. Sections of the metastases in the liver showed an identical appearance.

\section{Comment}

This tumour was typical of its kind in that it presented itself as a cause of acute retention in an infant (of 11 cases reported 8 have occurred in infants) and that it proved fatal within 5 months (average $6 \frac{1}{2}$ months).

This case is unusual in that distant metastases were found. Their structure was identical with that of the tumour. Distant metastases have been described in only one preceding case - that of Mackenzie and Chase (1928).

I wish to thank Mr. J. W. Riddoch, honorary surgeon, in whose charge this patient was treated, for encouragement to publish this case; Dr. A. G. Marshall, pathologist to the Corbett Hospital, who performed the necropsy and supplied the histological report; and Dr. W. Whitelaw, Birmingham, who kindly provided the microphotographs, and who permits me to say that he agrees with the diagnosis.

\section{REFERENCES}

Khoury, E. N., and Speer, F. D. (1944). J. Urol., 51, 505.

Mackenzie, D. W., and Chase, W. H. (1928). J. Urol., 19, 315.

Minchin, E. (1947). British Medical Journal, 2, 94.

\section{STREPTOMYCIN IN NON-TUBERCULOUS INFECTIONS}

\section{SUMMARY OF A REPORT TO THE MEDICAL RESEARCH COUNCIL}

BY

CLIFFORD WILSON, D.M., M.R.C.P.

Professor of Medicine, University of London; Director of the Medical Unit, the London Hospital

In December, 1946, the Medical Research Council appointed a committee* to arrange clinical trials of streptomycin in non-tuberculous infections, in parallel with the trials in certain forms of tuberculosis which have been organized by another committee of the Council. The trials in non-tuberculous infections began at five centres in London and later were extended to eleven centres throughout the country. This report summarizes the pooled results of the investigation; more detailed results will be published by individual observers. Because of the small amounts of streptomycin available, the relative rarity of suitable cases, and the wide diversity of conditions treated, experience of most infections in which streptomycin therapy may be effective is still limited. Even when, as in Haemophilus influenzae meningitis, a reasonably large series has been studied, the distribution of cases over so many centres has led to unavoidable variations in case selection, therapeutic procedure, and bacteriological control. For these reasons present claims must be guarded. Nevertheless, some clear-cut results have been obtained and profitable lines for further inquiry have been indicated.

These trials have been restricted to infections resistant to other forms of therapy in which bacteriological control

* Professor Sir Alexander Fleming (chairman), Professor Ronald V. Christie, Professor L. P. Garrod, Mr. R. Vaughan Hudson, Professor H. Raistrick, Dr. Robert Cruickshank, Dr. F. C. O. Valentine, Dr. F. R. Selbie, Professor Clifford Wilson (secretary). of treatment has been possible. With few exceptions the infecting organism has been proved streptomycin-sensitive before treatment has been begun; occasionally-e.g., in infective endocarditis-when penicillin treatment has failed, subsequent attempts to isolate the organism have been unsuccessful.

The chief value of streptomycin (apart from tuberculosis) lies in the treatment of penicillin-resistant infections due to the Gram-negative bacilli, particularly $H$. influenzae. Proteus, Pseudomonas pyocyanea, and Bact. coli. The clinical disorders in which treatment has been most effective are septicaemias, meningitis, urinary-tract infections, and local (superficial) infections.

\section{H. Influenzae Meningitis}

The results of preliminary trials in the United States suggested that streptomycin might be particularly valuable in this condition; a standard scheme of treatment was therefore recommended in the present investigation.

Dosage.-Intramuscular, $20 \mathrm{mg}$. per $1 \mathrm{lb}$. $(0.45 \mathrm{~kg}$.) body weight daily in divided (four-hourly) doses; Intrathecal (in saline), 50-100 mg. initial dose, according to age, and $25-50 \mathrm{mg}$. on subsequent days. Treatment was continued for at least seven days after cerebrospinal fluid became sterile.

Results.-Forty-three cases were treated with streptomycin. Four of these also received sulphonamides, penicillin, or serum ; in five others the C.S.F. was reported sterile before streptomycin injections were started. Of the remaining 34 cases, the infection was controlled in 25 $(74 \%)$, while treatment failed in nine. There was no significant difference in age, duration, or C.S.F. changes between the two groups, but clinically the unsuccessful cases appeared to be more severe. Where typing was carried out the organism was found to be Pittman type $b$. When treatment was successful the C.S.F. usually became sterile within 24 hours of the first intrathecal injection. Streptomycin was effective in 13 cases which had relapsed on other treatment and in nine cases in which the infection had been present for two weeks or longer. Four patients relapsed after an initial response to streptomycin, but the organism remained sensitive and further treatment with streptomycin alone was successful. The principal cause of failure was the development of resistance by the organism ; this occurred in seven of the nine failures, sensitivity changing from 0.5 to as high as 5,000 units in one to four days.

From this series it appears that streptomycin alone is probably as effective in $H$. influenzae meningitis as any other form of treatment at present available. The development of resistance is, however, a serious drawback, and it has been decided in future trials to use a combination of streptomycin, penicillin, and sulphonamides from the start.

\section{Other Forms of Meningitis}

Fourteen cases of meningitis due to penicillin-resistant bacteria have been treated with streptomycin. The causative organisms included Bact. coli, Ps. pyocyanea, Staph. pyogenes, Proteus, and Str. faecalis. In the majority of cases the meningitis developed after operation for cerebral abscess or cerebral tumour. The infection was controlled in 11 instances. Streptomycin is therefore a valuable new therapeutic agent in pyogenic meningitis due to penicillinresistant organisms.

\section{Other Infections}

Septicaemias.-Five cases of subacute bacterial endocarditis due to Str. viridans or $\boldsymbol{H}$. influenzae and one case of uncertain nature have been treated. With the exception 